\title{
History of Social Networks: From the Era of Bartering to the Collaborative Economy
}

\author{
Christophe Assens \\ Université Paris-Saclay
}

This article aims to provide a historical overview of the notion of a network and its effects in the realm of management. Originally deriving from the technical sphere with graph theory in mathematics, the concept of a network has progressively been extended to the social sphere where its ramifications have been the sharing of social capital. As technology has developed in terms of transportation and communication, social networks have gradually structured the economy more and more by increasing trust and thus reducing the uncertainty involved in trade. Today, these social networks have taken on a new dimension through social media, based in internet platforms that bring together billions of anonymous people in the collaborative economy. Despite all these developments over the centuries, networks still have the same universal function: they are sustainable structures for collaboration with intermediaries that guarantee trust.

Keywords: network, collaboration, trust, gift, management

\section{INTRODUCTION}

Networks have never been quite so present in society as they are in our day and age: "social networks" on the internet, transportation networks, innovation ecosystems set up in various domains, etc. The need to create connections between individuals can be explained by two phenomena: globalization, which forces us to have a more open economy, without boundaries, where States, administrations, and businesses are connected through shared interests; and technology, which allows us to recreate communities where people live together on a human scale, but at a distance, across international borders.

In other words, we are witnessing an inexorable revolution where networks tend to challenge traditional institutions in all domains: in politics, where digital networks form an "electronic democracy" led directly by citizens; in society, where adolescents' socialization takes place more and more on electronic platforms instead of with family and at school; and in economics, where businesses change their business model to suit opportunities related to electronic trade.

So as to better understand this reality in the business world, in this article we plan to go back in time and study the notion of a network, beginning with its etymological origins and going all the way to its most recent applications with the impact of digital technology on communication.

Through this progression and by taking a step back from looking at these phenomena from a managerial standpoint, it is possible to understand why the notion of a network has always left its mark on economic history. In our day and age, networks have truly become a precious interpretive framework for understanding the evolution of contemporary management, in that the creation of wealth relies more on 
intangible capital, such as reputation or trust (Alter, 2010), than it does on tangible resources and professional skills.

\section{THE SEMANTICS OF A NETWORK}

\section{The Function of Netting}

The French word for network, "réseau," comes from the Latin "retiolus," which is a diminutive of retis, which means net. It may also be associated with the notion of a "reticulum," which means little net, as this gave birth to noun reticule and to the French adjectives réticulé and réticulaire, which means reticulated and reticular, respectively. Thus, the notion of a network refers to objects that look like a net.

These origins of the word network date back to ancient history. The principle of netting was highlighted as early as the $1^{\text {st }}$ century $\mathrm{BC}$, by gladiators who used a net, a "reta," to immobilize their opponents. Following this, we encounter the word "resel" in the $12^{\text {th }}$ century BC; this word refers to the net used for hunting small animals. Historically, we see a fundamental characteristic of networks in this connection to the function of netting: a solid, organized system where the strings of mesh intersect, with free-flowing circulation between the links.

This net analogy was used by Musso (1997) in his description of networks, where he explains that a fishing net, like a gladiator's net, holds on to things and at the same time lets water flow through. This duality is specific to a net: being able to imprison objects and at the same time let other things flow freely.

The meaning of the word network then evolved with the development of weaving. It was both a technical and mainstream word used by weavers and basket makers to designate the interlacing of textile or plant fibers (Guillerme, 1988). During the Middle Ages, and also in the Encyclopedia of Diderot and d'Alembert, there was thus a slight change in the definition of a network. We went from a net to textiles, with silk made up of links and stitches. This woven piece of clothing will cover a person, while at the same time allowing air to pass through. It thus has the same distinctive feature as a net.

During the $16^{\text {th }}$ century, nets were sewn more tightly, giving rise to mesh bags. In French, they were called "réseuls," which over time became "résilles"- "hairnets" in English—which generally was a term that designated nets with wide stitching for holding women's hair.

Starting in the $18^{\text {th }}$ century, this concept was applied to different domains, this time in crystallography and spatial cartography. Networks became useful in topography for carrying out triangulation in a spatial context, which is still relevant when it comes to goniometry, and in particular geopositioning using cellular location tracking. In line with these applications in geography, mathematicians use networks in graph theory for measuring and optimizing flow in a geometric figure. The work of mathematician Sainte-Laguë (1941) illustrates this development.

\section{Circulation of Flow}

Thereafter, networks were no longer used to designate a united, indivisible system, but rather a system of nodes at a distance from one another, through which flow circulates.

From this period of time through the end of the 20th century, various technological developments (railroads, electricity, and then computing and digital technology) reinforced this idea of flow circulating between different areas. People then encountered issues with network externalities, such as reducing costs and the time it takes to communicate, move about, and distribute goods and services. As progress was made in computer science, we gradually moved from the concept of a mechanical network controlled by human will to an organic network capable of freeing itself from human will, presaging the coming of artificial intelligence, as Parrochia (2005, p. 78) points out: "in computer science, we see the appearance of random graphs, queueing networks, Petri nets, and then, following progress in algorithms and the mastery of multilayer networks, artificial neural networks, which were behind the resurgence of the connectionist paradigm in the 1970s-1980s." 


\section{Netting and Flow: Modern Recognition of Networks}

The meaning of the word network as we know it nowadays, which brings together the ideas of dense netting and flow, came about as a result of scientific discoveries and technical developments. Historically, the term was used by artisans, and it was specific to manual labor. With the industrial and scientific era, we moved on to a universe of engineering and scientists.

According to Musso (1997), this semantic change affected the spread and usage (which was sometimes improper) of the word network in language. According to this author, networks were directly impacted by the complexity of human nature. Musso (2005) maintains that the more a society grows and develops, the more technical and complex it becomes. It is thus natural for humanity to be a model for the organization of networks, as there is nothing more complex than humanity. He points out three phases that support this theory:

- The biometaphysical phase: networks are metaphysical and divine. They allow for humanity to be understood through mythology. They are thus naive attempts to understand and become closer to deities.

- The biopolitical phase: society is regulated in the same way as biology. For example, a network of blood vessels is compared to the circulation of money in the economy.

- The biotechnological phase: the apogee of networks, as they are used in all spheres; they become the method for explaining any social change by linking variables which had until now been isolated, using technological communication tools.

We will now examine how the notion of networks left the purely technical sphere, where it was inspired by scientific theories, and entered the social sphere. In particular, we will study the ways in which the work of Saint-Simon inspired the creation of a more egalitarian society despite territorial disparities, by connecting citizens with transportation and distribution networks.

\section{SOCIETY AS A NETWORK}

Starting in the Middle Ages, the notion of a network moved out of the technical register and began to play an essential role in the generation of knowledge, thus going hand in hand with the first social revolutions.

\section{From the Cloister to the Renaissance}

On this subject, Aboiron and Nicoulaud (2008) explain that social progress in the Middle Ages was based in the thoughts and reflections of the clergymen. These people belonged to various Franciscan and Dominican religious orders, which formed rival communities and attempted to influence the sovereign power. In this era, meditation in cloisters (clustri) was, of course, conducive to the maturation of ideas through reading, but it did not promote empirical experimentation and was even less favorable to the circulation of knowledge, because the monks traveled very little.

Nevertheless, in certain situations, either out of necessity or by choice, these clergymen moved about for religious missions, which led them to exchange views with their counterparts in other cloisters (Parrochia, 2005). Starting at the end of the 10th century, missionary monks popularized the practice of pilgrimages all throughout Europe and thus participated in connecting different cloisters, through the exchange of relics and manuscripts. This practice enabled the rise of bank and mercantile networks during the Renaissance, thanks to the diffusion of, sharing of, and confrontation with knowledge.

In this page in history, we find foundational elements of social networks, such as autonomy and mutual dependence. As a matter of fact, we see that the clustri were very independent and tied to their religious orders, as was the case for Cluny Abbey, but that they also needed to exchange with the pilgrims from other religious orders to obtain more knowledge. All religious orders were united by the Christian faith, which led them to interact in a connected way, despite their rivalries. 


\section{Saint-Simon's Ideal Society}

Beginning in the 19th century, a new phase began! This phase consisted of the social migration from the countryside to cities, and it forced people to rethink city planning, with the appearance of railroad networks and the first water supply networks as of 1830 in France. This period of time was inspired by Saint-Simon's "philosophy of networks," according to Musso (2005). According to Saint-Simon's humanist ideas, the privileges stemming from social standing were sources of injustices inherited from the old regime. It was thus right to do away with all privileges, on a secular basis, using principles of fraternity and mutual aid between citizens.

Saint-Simon used the characteristics of a network to outline an egalitarian society, which replaced the metaphor of the mythological tree, which had proclaimed that there exists a hierarchy of people where deities are at the top: "In this way, the concept of a network allowed Saint-Simon to structure all of his thoughts and carry out a symbolic operation: using this concept, he could bring the sciences together with myths and exclude God from his consideration, thus giving humanity the opportunity to claim ownership of these myths using reason." (Zetlaoui, 2003, p. 96).

From this point of view, Saint-Simon used networks as a vehicle for social emancipation. He saw citizens as forming links of a chain of solidarity, fueled by mutual respect and trust. Without this solidarity, the structure of our society would collapse. According to Saint-Simon, in this "philosophy of networks," each citizen is a kindred spirit of the other citizens with the right to equality in the creation of society, and this right cannot be called into question by invoking a bloodline, for example.

Ever since that period of time, the social dimension of networks has gained traction relative to the technical dimension. In the rest of this article, we will examine the ways in which social networks transform our views of the economy and of business management.

\section{SOCIAL NETWORKS}

In economics, organizing into networks is very old, as it dates back to the age of bartering, when commercial exchange could not be realized using a monetary base and instead was based on trust between merchants. From this perspective, networks are neither modern nor old, because trust has always been the key to success in economics in all eras: in the non-monetary era, where barter was safeguarded by trust; and in the monetary era, where transactions are safeguarded by trust, as it reduces the costs associated with the dangers of opportunism.

Neoclassical economists consider people to be perfectly rational. At the same time, new practices for exchanging goods, as well as some old forms of trade, such as bartering, show that it is impossible to separate the rationality of a market transaction from the quality of the social connection involved.

In today's complex world, it is no longer a matter of optimizing economic choices as a homo oeconomicus, because this is no longer possible due to uncertainty. It is now a matter of forging social connections, as a homo reticulus, so as to best protect ourselves from crises, seize opportunities, and build an identity in our search for meaning. From this point of view, networking is an essential activity, allowing everyone to cultivate relational capital within social networks, as this is more precious than material assets.

In social networks, it is important to consider not only the number of contacts (which is essential for forming the nodes of the network) but also the quality of these connections.

\section{The Theory of Strong Ties and Weak Ties}

When talking about the quality of interpersonal relationships, we can draw from the work of Granovetter (1973), who asserts that there are two categories of ties between people: strong ties, which convey complete kinship and mutual trust within a limited circle; and weak ties, which are built outside of our circle of trust and which are sources of diversity in the information we gather.

For Granovetter (1973), it is not the strong ties that are sources of added value, but rather the weak ties, that is, the ties that we maintain on an infrequent basis with someone in the form of a relationship that is not consistent. For him, strong ties are sources of isolation because the same information circulates endlessly within a group without being renewed. Therefore, it is the weak ties that allow two groups to 
exchange views about themes and subjects that are unknown to each of them, thus promoting, for example, the spread of rumors, as Granovetter (1973, p. 1365) explains: "whatever is to be diffused can reach a larger number of people, and traverse greater social distance, when passed through weak ties rather than strong. If one tells a rumor to all his close friends, and they do likewise, many will hear the rumor a second and third time, since those linked by strong ties tend to share friends. If the motivation to spread the rumor is dampened a bit on each wave of retelling, then the rumor moving through strong ties is much more likely to be limited to a few cliques than that going via weak ones; bridges will not be crossed."

We thus assume that the relationships that broaden one's social horizons with other people are found in one's weak ties. Weak ties may serve as bridges between different social networks, within which it is possible to pool and share information in order to build social capital.

\section{Bourdieu's Definition of Social Capital}

One of the uses of a social network is to allow members to share their "address books," which constitute club goods, that is, resources that are specific to the network and that are neither transposable to the outside nor privatizable within the network. This matches Bourdieu's (1980, p. 3) definition of social capital: "social capital is the collection of current and potential resources that are linked to the possession of a lasting network of relationships, which may or may not be connected to institutions and are used for sharing knowledge and gratitude."

There are two concepts in this definition that should be retained: the feeling of belonging to a network is shared in a way that depends on the social affinities between members (directly or through an intermediary: a friend of a friend, for example); members feel gratitude and show solidarity for one another.

As a result, social networks on the internet are mainly technical networks used for communication because they bring together a number of machines or user accounts which are connected using technology and which share information with each other on the basis of weak ties, using Granovetter's (1973) definition: the users' professional standing, age, sex, etc. There is not necessarily any building of social capital, in the way that Bourdieu (1980) defines it, that occurs through the usage of platforms for discussion on the internet. Nevertheless, social networks on the internet reduce the importance of physical distances and facilitate communication between anonymous people all around the world.

\section{The Small World Theory}

Let us use the example of the "small world" experiment devised by Milgram (1967), who attempted to set up a bridge between people. The goal of the experiment at the time was to send a file by mail from one person to another randomly chosen person. To achieve this objective, it was necessary to determine the intermediaries that together formed an interpersonal chain. After having conducted this experiment, Milgram (1967) calculated that the average length of this chain was six intermediaries.

Using the same experimental principles, in 2011 Facebook carried out the same experiment in partnership with the University of Milan. This time, using a sample of 721 million people (which was the total number of users on this social network in 2011), the results showed that each person was linked technically, though not socially, to any other person on the internet by a chain made up of an average of 4.74 links. Thanks to long-distance communication networks, physical distances are being reduced, though the same is not necessarily true for social distances.

In fact, "social networks" on the internet are equivalent to social media in that they have the same function as the press, the radio, and television, because of the informational exchanges between senders and receivers, who do not necessarily know each other. In this anonymous context, cohesion is guaranteed mainly by technical interfaces for telecommunication, like for telephones or email. With this type of digital network, it is important to always be further extending the frontiers of communication to strengthen the influence of these platforms: Google, Apple, Facebook, and Amazon. This process is different for a social network made up of non-anonymous members, where each member's face is known by the others, like a selective club, the access to which is locked to make it more attractive.

Consequently, communication has become an essential dimension of social networks, sometimes at the expense of the depth of relationships and the nature of the messages being sent (Wiener, 1971). The free 
flow of information especially on the internet, has therefore been considered to be something of a new standard for freedom of expression and human rights. In this way, communication through digital networks is becoming an issue of general concern in terms of how it affects the free flow of information, and it most often masks commercial considerations. Everyone is demanding the right to be informed without worrying about the costs, such as the loss of privacy when it comes to data.

"Virtual communities" on the internet may in certain cases constitute an extension of the social networks that had been built between people in-person. They allow for actions to be taken more quickly and for distances to be reduced, but they do not necessarily qualify as "social networks" that are full of cooptation and solidarity.

This comparison between social media and social networks allows us to highlight a new parameter in the nature of networks that has to do with the unifying factor for its members: affectio societatis.

On this subject, Assens (2003, p. 53) explains that "the members of a network are inevitably united by a common denominator, some specific asset, which may turn out to be material (an activation threshold, procedures, technical standards, or interfaces) or immaterial (language, knowledge, values, rituals, or culture). This factor unites a network's members; it solidifies their relationships and makes the entire structure more stable".

If this unifying factor is only technical, then we must be in the context of social media; if the unifying factor is about identity and values, then we must be part of a social network. In the latter case, the unifying factor allows members to build relationships based in trust for example through gift giving.

\section{The Foundations of the Economics of Gifts}

According to Mauss (1950), professor of religious history from Polynesian ethnic group, gifts initiate a relationship that is delayed in time through the reciprocal gift that is called for in return, such that it becomes an exchange. Although gifts seem to be associated with a form of altruism, they actually create a moral debt for the receiver, who then owes the giver a gift in return. For the people involved, this tacit obligation to engage in reciprocity threatens their reputation, their honor, the legitimacy of their social standing, and even the legitimacy of their professional standing. This logic of "giving and giving back" thus tends to establish an ethical code based in solidarity, which allows relationships to be fortified, not on the basis of hierarchical subordination, but rather on the basis of mutual trust. In "archaic" societies in Polynesia and Melanesia, the ritual of reciprocal gift giving allows social harmony to be maintained.

The theory introduced by Mauss (1950) deals with how relationships function when they are based in exchange, are built over time, and remain uninterrupted. He admits that there may be imbalances between what is given and what is received, but these imbalances never interfere with the relationship in the long term. Putting these two acts into perspective thus shows that they do not meet the classical requirements for commercial exchanges. Indeed, these requirements are based not only upon the notion of rationality of the participant but also upon the principles of satisfaction of desires (giving so as to receive) and synchronous reciprocity (giving and receiving). Mauss's theory is thus based upon a social tie that goes beyond the simple utility of exchange. In this case, the people involved enter into a lasting relationship where the creation of a unique, strong social connection is at the heart of any transaction.

In analyzing this type of relationship, the author suggests an "overall" interpretation of the act, that is, he considers that the economic exchange is inseparable from other dimensions such as symbolism, identity, social matters, emotions, relationships, etc.

This notion of the whole is also connected to these people's personal and professional spheres. Indeed, when we talk about business management, it is also necessary to consider the nature of the game from the perspective of the people involved, which includes values, conventions, a code of ethics, the issue of reputation, symbols, identity, standards of conduct, etc. Thus, this leads us to consider any exchange, whether it be commercial or non-commercial, to be a part of the social activity of the participant. The transposition of Mauss's (1950) nonutilitarian philosophy to the market economy is in fact featured in Alter's (2010) and Caillé and Grésy's (2014) sociological work, and it is the cause of the infatuation with the collaborative economy. 


\section{THE COLLABORATIVE ECONOMY}

The capitalist economy functions within a patrimonial framework, within which people gather resources and skills in order to create wealth. This wealth then serves to acquire other resources and skills to improve the business's holdings and further its development. This structure has limits, since financial resources and raw materials are now rarer and more costly to get, and also because individual skills are not enough to lead to increases in productivity: "doing more with less."

Given these conditions, in order to continue to develop the economy at a time when talent and resources are becoming scarcer, it is appropriate to pay attention to a hidden, yet fundamental dimension of economic transactions: human relations. Every time a commercial transaction is realized, it furthers a social relationship that is conducive to a climate of trust. This trust then serves to develop cooperation and thus promote access to new resources or collective skills that were unimaginable within a patrimonial framework: "doing more with partners." In this way, the economy tends to be developed on the basis of sharing rather than exclusive ownership, through consumer networking. The collaborative economy is sustained by this principle, through carpooling, apartment swaps, bartering between private individuals, etc. More specifically, Schwienbacher and Larralde (2010) define four forms of collaboration in the collaborative economy between private individuals:

- Sharing of services: this allows needs to be met when it comes to providing services. This applies in particular to any and all rental services. For example, we could give the example of the sharing of vehicles between private individuals.

- Trading and redistributing goods: the most common ways of doing this in these types of communities are bartering, gifting, or resale.

- Community living: the principle here is supplying community members with intangible resources, such as time or skills. The most common initiatives are sharing work or living spaces, carpooling, home help, private lessons, etc.

- Financial solidarity: more commonly called "crowdfunding." This type of participatory financing mainly brings together private individuals who are all conscious of a single, unifying project that requires startup funding. On a different note, we could mention organizations for group buying here, where consumers come together to make group purchases.

To explain the rise in collaborative practices based on sharing, Bostman and Roo (2011) highlight the disposable and cumbersome nature of certain objects that are useless in everyday life. They also discuss the dissatisfaction that comes from being surrounded by an abundance of possessions. One of the emblematic examples of the nonsensical nature of property highlighted by these authors is a drill, which when used as a tool for home improvements is used an average of 13 minutes over the course of a lifetime!

An entire group within our society is thus adopting this practice of sharing the use of goods and services instead of coveting their property, as Rifkin (2014) points out. This change in consumer behavior is being fostered by collaborative platforms in the digital universe.

According to Bostman and Roo (2011), there are several factors behind the success of collaborative platforms. First of all, cultivating social connections is of major importance when it comes to finding meaning in a totally fragmented society. Relationships that are based in sharing and values of solidarity are an answer to this search for meaning. In addition, collaborative practices contribute to the preservation of resources that are diminishing in the environment. Finally, financial crises also lead consumers to streamline their expenses by searching for the least costly solutions, which are provided by the collaborative economy. As budgets get tighter, some people are forced to adopt this collaborative lifestyle: group buying to save money, or renting out their possessions to obtain additional resources. In the collaborative economy, the value of a transaction is no longer linked solely to the intrinsic value of the product, but also to the degree of trust built between anonymous people. The role of platforms is to guarantee this trust!

The collaborative economy does not apply only to consumerism, but also concerns other aspects of businesses' relationships with clients (Robert et al. 2014). For example, crowdsourcing ${ }^{1}$ is based on users 
sharing their experience. This pooling of knowledge may then feed discussion forums and thus contribute to the first stage of a business's customer service.

\section{CONCLUSION}

Weaving, linking, unifying, and creating flow: such are the properties of the concept of a network, which gradually evolved and moved from the technical sphere to the social sphere. Within a social framework, networks are useful because of their ability to unify the different participants of which they are composed, on the one hand respecting participant autonomy, but on the other hand fostering collaboration in the context of affectio societatis. This networking took on various different dimensions over the course of history: networking involving small-scale distances with the barter economy of merchants in the Middle Ages; networking involving mid-sized distances over vaster regions with the migration of religious pilgrims during the Renaissance (Aboiron et al., 2008); territorial networking on a larger scale with infrastructure networks for transportation, water, and electricity as imagined by Saint-Simon in the 20th century; and limitless networking in the digital age with collaborative platforms capable of uniting billions of anonymous people in the 21 st century.

Even though the distances have increased as a result of technological progress over the course of the centuries, social networks still have the same properties. The primary reason to become a part of a social network is sharing an "address book," which is like social capital that constitutes a club good, that is, a resource that is specific to the network and that is neither transposable to the outside nor privatizable within the network. To make the most of this social capital, it is necessary to be united and devise plans for building and maintaining trust, such as reciprocated gift giving (Mauss, 1950).

With the rise of tools for communicating at a distance and digital platforms, social networks have taken the form of social media. This term designates a network for communicating at a distance, without an intermediary between the sender and receiver of a message. In social networks, it is thus important to take into consideration not only the number of contacts involved but also the quality of these connections. When discussing the quality of interpersonal connections, we invoked the work of Granovetter (1978), who states that there exist two categories of relationships between people: strong ties, which involve much closeness and shared trust within a limited circle based on a particular affinity, and weak ties, which are developed in a more indirect and involuntary way outside of this primary circle of trust and which are sources of diversity of information.

For this author, it is not the strong ties that are sources of added value, but rather the weak ties, that is, the ties that we maintain on an infrequent basis with someone in the form of a relationship that is not consistent. For him, strong ties lead to isolation because the same information circulates endlessly within the group without being renewed. It is thus the weak ties that allow social media to exist on the internet, while strong ties guarantee that social networks are attractive to people and face-to-face communication allows people to build interpersonal trust.

For businesses, social media represent a major phenomenon that needs to be dealt with, primarily from an advertising and commercial perspective. Taking advantage of rumors on social media on the internet is thus an essential concern when it comes to adding value to a brand through viral marketing, using the crosscontamination of information between users, one step at a time. Likewise, it is becoming more important for any business to take advantage of the multiplicative effects of social networks on the sales of goods and services, for example, by attempting to take advantage of each member's address book through commercial sponsorship.

\section{ACKNOWLEDGEMENT}

Translated \& Edited by American Publishing Services (https://americanpublishingservices.com/). 


\section{ENDNOTE}

1. Neologism: crowdsourcing is a form of externalization where certain tasks that are traditionally carried out within the company are given to a "crowd." For example, Wikipedia, the online encyclopedia, operates using this crowdsourcing model by proposing to volunteer contributors that they write articles, while at the same time recognizing that participatory democracy has limits. For Wikipedia, a small number of active members monitor and censure the other members, who are relegated to a more passive rank.

\section{REFERENCES}

Aboiron, J., \& Nicoulaud B. (2008). L'émergence des pôles de compétitivité: Des cloîtres aux neurones. Revue du Panthéon, 2(3).

Alter, N. (2010). Donner et prendre: La coopération en entreprise. Paris, Editions La Decouverte.

Assens, C. (2003). Le réseau d'entreprises : vers une synthèse des connaissances. Management International, 7(4), 49-59.

Botsman, R., \& Roo, R. (2011). What's mine is yours: How Collaborative Consumption Is Changing The Way We Live. Harper Collins, Londres.

Bourdieu, P. (1980). Le capital social. Actes de la Recherche en Sciences Sociales, 31, 2-3.

Caillé, A., \& Grésy, J-E. (2014). La révolution du don. Paris, Editions du Seuil.

Granovetter, M.S. (1973). The strength of weak ties. American Journal of Sociology, 78(6), 1360-1380.

Guillerme, A. (1988). Genèse du concept de réseau 1760-1815. Territoire et Génie en Europe de l'ouest. Rapport pour le compte du Ministère de l'équipement et du logement. Délégation à la recherche et à l'innovation.

Mauss, M. (1950). Essai sur le don: Forme et raison de l'échange dans les sociétés archaïques. In Sociologie et Anthropologie. Presses Universitaires de France.

Milgram, S. (1967). The small world problem. Psychology Today, 1, 62-67.

Monnier, L., \& Thiry, B. (Eds.). (1997). Mutations structurelles et intérêt général. Paris, De Boeck.

Musso, P. (2005). Utopie et idéologie du réseau. Conférence introductive aux 5ème Rencontres de Mâcon Réseaux en question: Utopies, pratiques et prospective. Organisées par l'Institut de recherche du Val de Saône mâconnais. Mâcon.

Musso, P. (1997). Télécommunication et philosophie des réseaux, la postérité paradoxale de Saint-Simon (pp. 217-218). Paris, PUF.

Parrochia, D. (2005). Quelques aspects historiques de la notion de réseau. Flux, 4(62), 10-20.

Rifkin, J. (2014). La Nouvelle Société du coût marginal zéro: L'internet des objets, l'émergence des communaux collaboratifs et l'éclipse du capitalisme. Paris, Les liens qui libèrent.

Robert, I., Binninger, A-S., \& Ourahmoune, N. (2014). La consommation collaborative, le versant encore équivoque de l'économie de la fonctionnalité. Développement Durable et Territoires, 5(1).

Sainte-Lagüe, J-A. (1941). Du connu à l'inconnu. Paris, Editions Gallimard.

Schwienbacher, A., \& Larralde, B. (2010). Crowdfunding of small entrepreneurial ventures. The Oxford Handbook of Entrepreneurial Finance, edition Douglas Cumming, Oxford University Press, pp. 369-392.

Wiener, N. (1971). Cybernétique et Société. L'usage humain des êtres humains (édition synoptique). Paris, Union générale d'éditions,

Zetlaoui, T. (2003). Critique des réseaux, Pierre Musso (PUF 2003) ou la mort annoncée de la figure du réseau. Quaderni, 52(1), 123-128. 